Article

\title{
Development of Injectable PEGylated Liposome Encapsulating Disulfiram for Colorectal Cancer Treatment
}

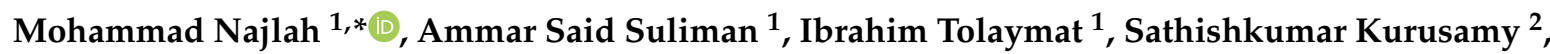 \\ Vinodh Kannappan ${ }^{2}$, Abdelbary M. A. Elhissi ${ }^{3}$ and Weiguang Wang ${ }^{2}$ \\ 1 Pharmaceutical Research Group, School of Allied Health, Faculty of Health, Education, Medicine and Social \\ Care, Anglia Ruskin University, Bishops Hall Lane, Chelmsford CM1 1SQ, UK; \\ ammar.said-suliman@anglia.ac.uk (A.S.S.); ibrahim.tolaymat@anglia.ac.uk (I.T.) \\ 2 Faculty of Science \& Engineering, University of Wolverhampton, Wolverhampton WV1 1LY, UK; \\ S.Kurusamy2@wlv.ac.uk (S.K.); v.kannappans@wlv.ac.uk (V.K.); w.wang2@wlv.ac.uk (W.W.) \\ 3 College of Pharmacy and Office of the Vice President (Research and Graduate Studies), Qatar University, \\ Doha, Qatar; aelhissi@qu.edu.qa \\ * Correspondence: mohammad.najlah@anglia.ac.uk; Tel.: +44(0)124568-4682
}

Received: 20 October 2019; Accepted: 11 November 2019; Published: 14 November 2019

\begin{abstract}
Disulfiram (DS), an anti-alcoholism medicine, shows strong anti-cancer activity in the laboratory, but the application in clinics for anti-cancer therapy has been limited by its prompt metabolism. Conventional liposomes have shown limited ability to protect DS. Therefore, the aim of this study is to develop PEGylated liposomes of DS for enhanced bio-stability and prolonged circulation. PEGylated liposomes were prepared using ethanol-based proliposome methods. Various ratios of phospholipids, namely: hydrogenated soya phosphatidylcholine (HSPC) or dipalmitoyl phosphatidylcholine (DPPC) and N-(Carbonyl-methoxypolyethylenglycol-2000)-1,2-distearoyl-sn-glycero-3-phosphoethanolamine (DSPE-PEG 2000 ) with cholesterol were used. DS was dissolved in the alcoholic solution in different lipid $\mathrm{mol} \%$ ratios. The size of the resulting multilamellar liposomes was reduced by high-pressure homogenization. Liposomal formulations were characterized by size analysis, zeta potential, drug loading efficiency and stability in horse serum. Small unilamellar vesicles (SUVs; nanoliposomes) were generated with a size of approximately 80 to $120 \mathrm{~nm}$ with a polydispersity index (PDI) in the range of 0.1 to 0.3 . Zeta potential values of all vesicles were negative, and the negative surface charge intensity tended to increase by PEGylation. PEGylated liposomes had a smaller size $(80-90 \mathrm{~nm})$ and a significantly lower PDI. All liposomes showed similar loading efficiencies regardless of lipid type (HSPC or DPPC) or PEGylations. PEGylated liposomes provided the highest drug biostability amongst all formulations in horse serum. PEGylated DPPC liposomes had $t_{1 / 2}=77.3 \pm 9.6 \mathrm{~min}$ compared to $9.7 \pm 2.3 \mathrm{~min}$ for free DS. In vitro cytotoxicity on wild type and resistant colorectal cancer cell lines was evaluated by MTT assay. All liposomal formulations of DS were cytotoxic to both the wild type and resistant colorectal cancer cell lines and were able to reverse chemoresistance at low nanomolar concentrations. In conclusion, PEGylated liposomes have a greater potential to be used as an anticancer carrier for disulfiram.
\end{abstract}

Keywords: disulfiram; copper; liposomes; colorectal cancer; chemoresistance; PEGylation

\section{Introduction}

The medical need for better cancer therapies is undiminished, while drug development is slow and costly, mainly due to the large risk of toxicity of novel molecules. Development of a new 
drug takes, on average, 15 years and costs US $\$ 1.5 \mathrm{bn}$, with only $5-25 \%$ of new oncology drugs in clinical development actually reaching the market [1]. This dilemma has led to a booming interest in repurposing of known drugs into new use in Europe and the USA [2]. Currently, over 30,000 drugs have been on the market. Considering their derivatives, this is a tremendously huge resource for drug repositioning.

Disulfiram (DS, Figure 1), a well-known anti-alcoholism drug that has been used safely for over 65 years, has shown potent anticancer activity against the aggressive form of colon, breast, lung, prostate, ovarian, cervical and brain cancers. Furthermore, this drug specifically and effectively terminates drug-resistant cancer stem cells (CSCs) and reverse chemoresistance [3,4]. DS also has a significant synergic cytotoxicity with a wide range of first-line anticancer drugs such as cisplatin, 5-flurouracil, paclitaxel, gemcitabine, doxorubicin and temozolomide in vitro and saves normal cells in kidney, gut and bone marrow in vivo by increasing the therapeutic index [5-7]. The anticancer activity of DS is copper (II)-dependent as DS strongly chelates $\mathrm{Cu}$ to form a DS/Cu complex [8] (Figure 1). Cancer tissues possess significantly higher copper levels than their normal counterparts [9]; this may grant DS the selectivity to target cancer cells [10]. Although DS shows strong anticancer activity in laboratory, its application in cancer clinics is highly limited by its bio-instability. The half-life of DS in the blood stream is less than $4 \mathrm{~min}[11,12]$.

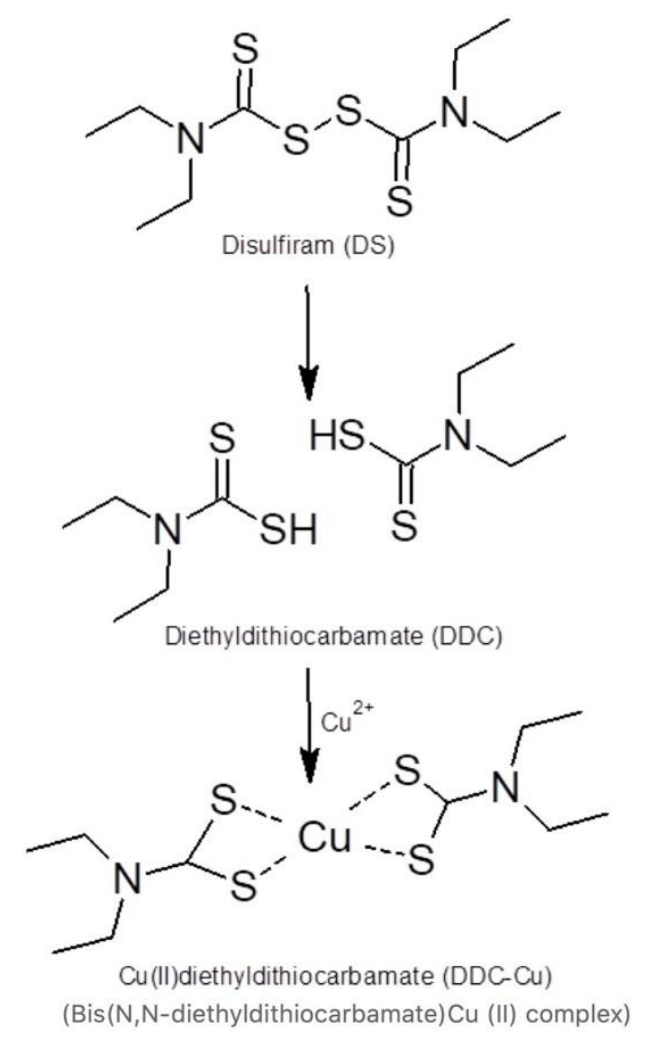

Figure 1. Disulfiram (DS) reaction with copper.

The rapid degradation is the major challenge faced when using DS in cancer therapy. Our work demonstrated that the intact thiol groups in DDC are essential for chelating $\mathrm{Cu} 2$ and targeting cancer [13]. Currently, only an oral version of DS is available in clinics. The thiol groups are instantly methylated or glucuronidated in the liver. While the DS metabolites are active against alcoholism, the anti-cancer activity does require unmodified DS [13]. The development of an efficient delivery system able to protect DS during its circulation into cancerous cells is essential. There has been a growing interest in developing nano-drug-delivery systems that are able to provide sufficient protection to DS, thus, enabling clinical trials [14]. 
Liposomes are nanocarrier systems made of relatively stable and cheap compositions and prepared by hydration of phospholipids known to be non-toxic, biodegradable, biocompatible, and non-immunogenic $[15,16]$. The unique structures of liposomes make them capable of encapsulating both hydrophilic and lipophilic drugs $[17,18]$. For example, Wang et al. have successfully encapsulated DS into liposome (Lipo-DS) and managed to mildly extend the half-life of DS in the bloodstream to approximately $20 \mathrm{~min}[3,19]$. However, more development is required in this field, especially for enhancing the loading efficiency and extending the stability of DS [14]. For example, developing long-circulating drug delivery systems that might have a potential for translation to cancer therapy. Furthermore, the instability of liposomes owing to liability of its compositions to hydrolysis, oxidation and microbiological contamination needs to be overcome.

One approach to preparing liposomes is by using the proliposome technology as stable precursors that can instantly generate vesicles prior to formulation administration [20]. Ethanol-based proliposomes are based on using ethanolic lipid solutions to facilitate the hydration of phospholipids and generate oligolamellar or multilamellar liposome vesicles [21]. Proliposomes represent an economical approach to scale-up liposome production and resolve the instability problems associated with conventional thin-film-made liposomes. These advantages are attributed to the predominance of the ethanolic phase in proliposomes instead of water, avoiding phospholipid hydrolysis and offering self-antimicrobial preservation [22,23].

In this study, we have developed injectable DS-loaded PEGylated liposomes for colorectal cancer treatment. Ethanol-based proliposome technology was used to prepare DS-loaded liposomes with various lipid compositions. The prepared formulations were characterized by particle size; particle size distribution; zeta potential and drug entrapment efficiency. Additionally, the cytotoxicity of the PEGylated liposome encapsulated DS was examined in both 5-fluorouracil sensitive (H630 $\left.0_{\mathrm{WT}}\right)$ and resistant $\left(\mathrm{H} 630_{\mathrm{R} 10}\right)$ colon cancer cell lines.

\section{Materials and Methods}

\subsection{Materials}

Hydrogenated phosphatidylcholine (HSPC; Phospholipon 90H), dipalmitoyl phosphatidylcholine (DPPC) and N-(Carbonyl-methoxypolyethylenglycol-2000)-1,2-distearoyl-snglycero-3-phosphoethanolamine, (DSPE-PEG 2000 ) were obtained from Lipoid, Steinhausen, Switzerland. Tetraethylthiuram disulfide or disulfiram (DS) (97\% pure) and Tween ${ }^{\circledR} 80$ were purchased from Acros Organics, Loughborough, UK. Dulbecco's modified Eagle's medium (DMEM), non-essential amino acid solution and L-glutamine (cell culture tested, 99.0-101.0\%), Trypsin-EDTA solution, ethanol (absolute and 70\%), 96-well plates (sterile with lids), $50 \mathrm{~mL}$ centrifuge tubes (sterile), tissue culture flask $75 \mathrm{~cm}^{2}$ (sterile) and serological pipettes (sterile) were obtained from Fisher Scientific, Loughborough, UK. Cholesterol (Ch; $\geq 99 \%$ ), glass vials $(15 \mathrm{~mL})$, fluorouracil ( $5 \mathrm{FU})$, dimethyl sulfoxide (DMSO), thiazolyl blue tetrazolium bromide, fetal bovine serum (FBS), phosphate-buffered saline (PBS) tablets, trypan blue solution ( $0.4 \%$ liquid, sterile filtered), syringe filters $(0.2$ and $0.45 \mu \mathrm{m})$, syringe needles and sterile pipette tip boxes were purchased from Sigma Aldrich, Dorset, UK. Horse Serum, New Zealand origin was purchased from Gibco, Fisher Scientific, Loughborough, UK. Colorectal cell line $\left(\mathrm{H} 630_{\mathrm{WT}}\right)$ and acquired resistance to $10 \mu \mathrm{M}$ 5FU colorectal cell line (H630 10 ) were obtained from Professor Weiguang Wang Group, University of Wolverhampton, Wolverhampton, UK. All other reagents were of pharmaceutical grade and used as received.

\subsection{Methods}

\subsubsection{Preparation of Liposomes}

Liposomal formulations were prepared using the ethanol-based proliposome method reported previously [20]. The lipid phase (phospholipid: Ch; 1:1 mole ratio) (300 mg) was dissolved in absolute 
ethanol $(300 \mu \mathrm{L})$ at $70{ }^{\circ} \mathrm{C}$ (water bath) for $1 \mathrm{~min}$ within a $30 \mathrm{~mL}$ glass vial. For the PEGylated liposomes,

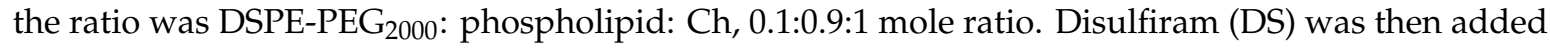
in the ethanolic solution to produce a range of concentrations as mol\% of the ultimate lipid phase $(0,5,10$ and $15 \mathrm{~mol} \%$ of the lipid phase, Table 1$)$. Aqueous (water) phase $(30 \mathrm{~mL})$, heated significantly above the Tm of the lipid, was added immediately to avoid lipid phase solidification. Liposomes were generated upon vigorous hand shaking and vortex mixing (Grant-bio PV-1, Shepreth, UK) for 5 min. Liposomal formulations were then kept for annealing above the phase transition temperature of the lipids for $2 \mathrm{~h}$ followed by size reduction.

Table 1. The ingredients of DS liposomal formulations.

\begin{tabular}{|c|c|c|c|c|c|c|}
\hline Formulation & Ingredients & DSPE-P & HSPC & DPPC & $\mathrm{Ch}$ & DS \\
\hline \multirow{4}{*}{ HSPC:Ch } & $0.0\left(\mathrm{~mol}^{\%}{ }^{*}\right)$ & - & $1 * *$ & - & 1 & - \\
\hline & 5.0 & - & 1 & - & 1 & 0.11 \\
\hline & 10.0 & - & 1 & - & 1 & 0.22 \\
\hline & 15.0 & - & 1 & - & 1 & 0.36 \\
\hline \multirow{4}{*}{ PEG:HSPC:Ch } & 0.0 & 0.1 & 0.9 & - & 1 & - \\
\hline & 5.0 & 0.1 & 0.9 & - & 1 & 0.11 \\
\hline & 10.0 & 0.1 & 0.9 & - & 1 & 0.22 \\
\hline & 15.0 & 0.1 & 0.9 & - & 1 & 0.36 \\
\hline \multirow{4}{*}{ DPPC:Ch } & 0.0 & - & - & 1 & 1 & - \\
\hline & 5.0 & - & - & 1 & 1 & 0.11 \\
\hline & 10.0 & - & - & 1 & 1 & 0.22 \\
\hline & 15.0 & - & - & 1 & 1 & 0.36 \\
\hline \multirow{4}{*}{ PEG:DPPC:Ch } & 0.0 & 0.1 & - & 0.9 & 1 & - \\
\hline & 5.0 & 0.1 & - & 0.9 & 1 & 0.11 \\
\hline & 10.0 & 0.1 & - & 0.9 & 1 & 0.22 \\
\hline & 15.0 & 0.1 & - & 0.9 & 1 & 0.36 \\
\hline
\end{tabular}

* Drug lipid molar percentage. ${ }^{* *}$ Molar ratio.

\subsubsection{Size Reduction of Liposomes}

Liposome dispersions ( $30 \mathrm{~mL}, 10 \mathrm{mg}$ formulation/mL) was placed in the bench top NanoDebee high-pressure homogenizer (Bee International Inc., Northampton, UK) and processed for 10 cycles through seven reactors at 20,000 psi. Thereafter, liposome dispersions were placed on a magnetic stirring plate at $350 \mathrm{rpm}$ in a fume-hood to stir for $5 \mathrm{~h}$ to minimize the trace amounts of ethanol in the formulation.

\subsubsection{Photon Correlation Spectroscopy (PCS) Analysis after Size Reduction}

The photon correlation spectroscopy (PCS) technique relies on the Brownian motion of the particles using the Zetasizer instrument (Zetasizer nano, Malvern Instruments Ltd., Malvern, UK). The size and polydispersity of the homogenized liposomes were analyzed by recording the hydrodynamic diameter ( $Z_{\text {average }}$ ) and polydispersity index (PI), respectively, using the Zetasizer instrument (Zetasizer nano, Malvern Instruments Ltd., Malvern, UK).

\subsubsection{Determination of Drug Entrapment Efficiency}

Entrapment efficiency of DS was determined by adapting the separation methods previously reported $[24,25]$. One $\mathrm{mL}$ of liposome suspension was passed through a syringe filter (Durapore ${ }^{\circledR}$ Membrane PVDF Filters, HVLP02500, $0.45 \mu \mathrm{m}$, Hertfordshire, UK) followed by injecting $2 \mathrm{~mL}$ distilled water to wash the filter. The filtrate $(0.5 \mathrm{~mL})$ was add to $1.5 \mathrm{~mL}$ of methanol. The mixture was bath sonicated (Fisherbrand ${ }^{\mathrm{TM}}$ 112201, Loughborough, UK) for $2 \mathrm{~min}$ to disrupt the liposomes and release the entrapped drug. To determine the total amount of DS in liposome formulation, $1 \mathrm{~mL}$ was diluted directly by $2 \mathrm{~mL}$ distilled water, and $0.5 \mathrm{~mL}$ of the resulting suspension was treated by methanol following the same steps described above. HPLC analysis reported by Najlah et al. [14] was performed 
on an UltiMate 3000 UHPLC (Thermo Fisher Scientific UK, Loughborough, UK) with a Phenomenex Luna C18 4.6 $\times 150 \mathrm{~mm}$ column with a $5 \mu \mathrm{m}$ particle size (Phenomenex, Torrance, CA, USA). The mobile phase comprised $80 \%$ HPLC grade methanol and 20\% HPLC grade water. The flow rate was $1 \mathrm{~mL} / \mathrm{min}$, whereas UV detection was performed at a wavelength of $275 \mathrm{~nm}$ with an injection volume of $20 \mu \mathrm{L}$.

The solubility of DS in water is less than $4.5 \mathrm{mg} / \mathrm{L}[11,26,27]$. Therefore, the amount of the drug dissolved in water during hydration was ignored. However, any traces solubilized during the process were excluded by following the same dilution factor for both the entrapped and total drug calculations. The entrapment efficiency (EE) of DS in liposomes was calculated using the following equation:

$$
\mathrm{EE}(\%)=(\text { Amount of DS entrapped/Total amount of DS in liposomal suspension }) \times 100
$$

The drug loading efficacies (DLE\%) were calculated by the following equation [28]:

$$
\text { DLE }(\%)=(\text { Amount of DS entrapped/Theoretical DSF content in liposome }) \times 100 \%
$$

\subsubsection{Stability of Encapsulated Disulfiram in Horse Serum}

A sample $(0.5 \mathrm{~mL})$ of liposome formulation $\left(10 \mathrm{~mol} \%\right.$ formulation) was preheated at $37^{\circ} \mathrm{C}$, added to $2 \mathrm{~mL}$ of horse serum (preheated at $37^{\circ} \mathrm{C}$ ) and incubated in a shaking water bath at $37^{\circ} \mathrm{C}$ (Grant OLS Aqua Pro, Shepreth, UK) and $100 \mathrm{rpm}$. For free DS, $25 \mu \mathrm{L}$ of $4 \mathrm{mg} / \mathrm{mL}$ DS in DMSO was pipetted in to $2 \mathrm{~mL}$ of horse serum diluted with $475 \mu \mathrm{L}$ of distilled water (preheated at $37^{\circ} \mathrm{C}$ ). At specific time intervals, aliquots of $200 \mu \mathrm{L}$ were added to $500 \mu \mathrm{L}$ of ethanol and vortexed for $1 \mathrm{~min}$. The mixture solution was centrifuged at 10,000 $\mathrm{g}$ for $10 \mathrm{~min}$ (Heraeus Fresco 17, UK). The supernatant "A" was collected and the pellet was re-suspended in 0.5 methanol vortex for $30 \mathrm{~s}$ and heated in the water bath $37^{\circ} \mathrm{C}$ for $2 \mathrm{~min}$, then vortexed for $30 \mathrm{~s}$ again and centrifuged at $10,000 \times \mathrm{g}$ for $10 \mathrm{~min}$. The supernatant "B" was collected, added to supernatant "A" and analyzed by HPLC using the methods reported above. For the control, the same formulation and previous steps were followed, but by replacing the horse serum with distilled water. The control was used as $100 \%$ for the stability calculations.

\subsubsection{Cytotoxicity Study (MTT Assay)}

The H630 ${ }_{\mathrm{WT}}$ (passage 13-27) and $\mathrm{H} 630_{\mathrm{R} 10}$ (passage 4-16) cells were seeded in 96-well plates at seeding density of $1 \times 10^{4}$ cells/well in Dulbecco's modified Eagle's medium (DMEM) with $10 \%$ FBS, $1 \mathrm{mM}$ sodium pyruvate, $2 \mathrm{mM}$ L-glutamine and $0.1 \mathrm{mM}$ non-essential amino acids. Cells were incubated at $37^{\circ} \mathrm{C}, 5 \% \mathrm{CO}_{2}$ and $95 \%$ relative humidity. Cells were constantly exposed to different concentrations of the $10 \% w / w$ DS-loaded liposomes in combination with $10 \mu \mathrm{M}$ of $\mathrm{CuCl}_{2}$ for $72 \mathrm{~h}$ and then subjected to a standard 3-(4,5-Dimethylthiazol-2-yl)-2,5-Diphenyltetrazolium bromide (MTT) assay as previously described [29]. Free DS has been used as a positive control. The experiments were carried out in triplicates and the $\mathrm{IC}_{50}$ values were calculated. For combination studies, cells were exposed simultaneously to similar concentration range of DS and paclitaxel (1-250 nM) and DS $(1-250 \mathrm{nM})$ and $5 \mathrm{FU}(1-250 \mu \mathrm{M})$.

\subsubsection{Statistical Analysis}

Statistical significance was measured using the one-way analysis of variance (ANOVA) and student's t-tests, as appropriate. All values were expressed as the mean \pm standard deviation. Values with $p<0.05$ were regarded as significantly different.

\section{Results and Discussion}

Several DS liposomal formulations were prepared using three phospholipids HSPC, DDPC or DSPE-PEG 2000 , with cholesterol (Ch) in 50:50 lipid:Ch molar ratios (Table 1). We have reported in a previous study that liposomes prepared at an equimolar ratio of lipid:Ch using ethanol-based proliposome technology were able to act as potential carrier of the highly hydrophobic anticancer 
drugs [20]. DS was included in the liposomal formations at a molar percentage ranging from 0 to $15(\mathrm{~mol} \%)$ of the lipids (Table 1$)$.

\subsection{Size Analysis of Liposomes}

In recent decades, a few techniques have been predominantly employed to reduce the size of liposomes into the nano range, such as probe sonication [30], membrane extrusion [31] and high-pressure homogenization [32]. We have previously reported that high-pressure homogenization (HPH) might be more advantageous than probe sonication; $\mathrm{HPH}$ produced vesicles with a similar drug entrapment efficiency and superior homogenization output rate [23]. Furthermore, HPH overcame problems associated with probe sonication such as sample contamination (with titanium particles leached from the probe) and overheating [23]. In this study, HPH was used to reduce the size of liposomes and transform large multilamellar vesicles (MLVs) into smaller unilamellar vesicles (SUVs, $100 \mathrm{~nm}$ ).

As shown in Figure 2a, HPH was successfully employed to produce liposomes with a range of sizes around $100 \mathrm{~nm}$. For all formulations, the drug inclusion had no significant impact on liposome size $(p>0.05)$. Similarly, the size of produced vesicles was not affected by lipid phase composition as there were no significant difference $(p>0.05)$ amongst HSPC formulations and their corresponding DPPC formulations. Noteworthy, the average size of non-PEGylated formulations (both HSPC and DPPC) was about $100 \mathrm{~nm}$, while the average size of PEGylated formulations was around $80 \mathrm{~nm}$. This might be considered as a general trend that similar size reduction methods can produce PEGylated liposomes that are smaller than their non-PEGylated counterparts. This trend has been confirmed in the literature and explained by the increased intensity of lateral repulsion caused by the addition of PEG to the lipid bilayers (i.e., the lipid bilayer will curve; this will reduce the size of vesicle). Furthermore, PEGylation decreases lamellarity as a result of increased interlamellar repulsion [33]. Nonetheless, in this study, no significant difference was proven by the statistics (Figure 2a).

(a)

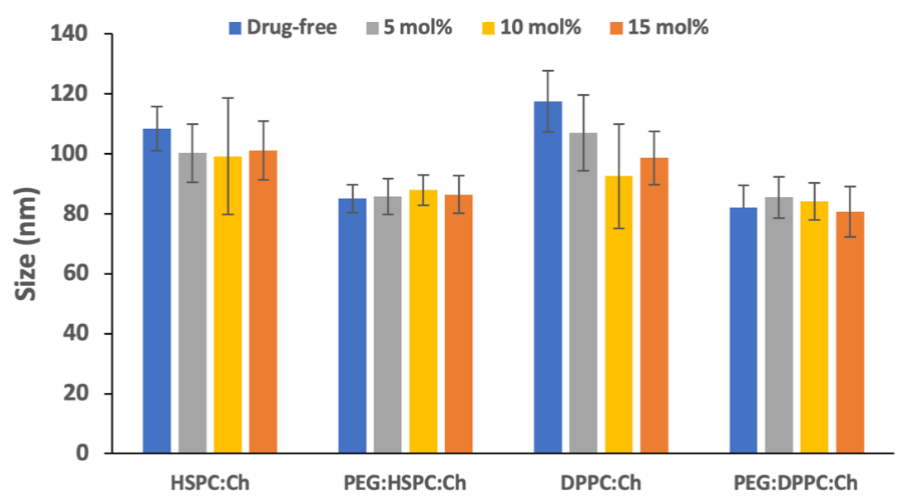

(b)

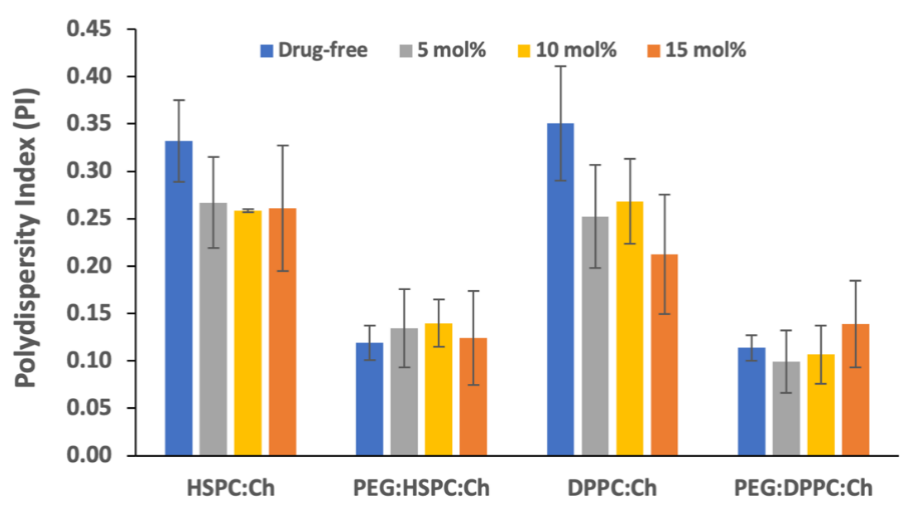

Figure 2. Size ( $\left.Z_{\text {average }}\right)(\mathbf{a})$ and PI (b) of liposomes after high-pressure homogenization with a range of DS concentrations $(n=3 \pm \mathrm{SD})$. 
It has been reported that the size of liposomes might be influenced by the degree of phospholipid saturations, and the charge and/or the length of the chain of their lipid components $[20,34,35]$. In this study, the only difference between both phospholipids is the chain length (16 and 18 for DPPC and HSPC, respectively); hence, no significant changes in the measured size were shown. Differently, we have reported previously that paclitaxel (PTX)-loaded liposomes made from HSPC had larger sizes than that made from DPPC [20]. This might be due to different strength in drug-lipid-bilayer interactions between both sets of formulations.

$\mathrm{HPH}$ has also generated liposomes with relatively narrow size distribution (i.e., low PI), regardless of lipid type, PEGylation and drug concentration (Figure $2 b$ ). The polydispersity index (PI) for all liposomes was found to be below 0.35 (Figure 2b). However, PEGylation was found to produce liposomes of narrower PIs $(p<0.05)$ than that of the conventional PEGylated liposomes, regardless of lipid type and drug concentration (Figure 2b). This is attributed to the superiority of PEGylated liposomes over conventional vesicles [36,37]. For non-PEGylated liposomes, the inclusion of DS resulted in liposomes with narrower PIs than that of empty liposomes. Surprisingly, no similar trend was observed for the PEGylated liposomes. This might be due to a less effective drug-bilayer interaction compared to the effect of PEGylation, leading to better curving of the bilayer, as explained above. It is noteworthy to mention that PI was independent of drug concentration for all loaded formulations (Figure 2b).

During the development stage of this method, our results showed that PI and size measurements were dependent on the number of homogenization cycles up to a certain number (data not shown). Conclusively, the low PI for all formulations indicates that the number of cycles selected was appropriate and no further high-pressure homogenization was required.

\subsection{Zeta Potential Analysis}

The zeta potential (ZP), the electrostatic charge of the particle surface, plays an important role in controlling the stability of colloids by the repulsive energy barrier opposing the aggregation of dispersed particles (e.g., liposomes) in buffer solutions [37,38]. The ZPs of all liposomes were negative, irrespective of formulation. Furthermore, for all formulations, insignificant effects $(p>0.05)$ of drug concentration on the zeta potential were observed (Figure 3). This may indicate that HPH produced stable nano-liposomes vesicles, as the electrostatic repulsion between negatively charged vesicles may reduce aggregation [38].

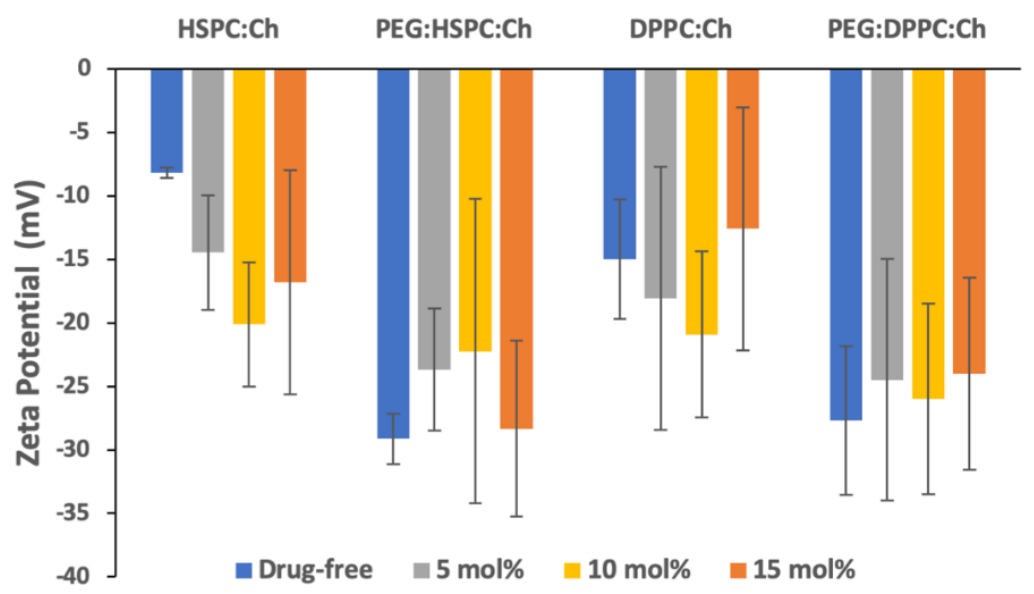

Figure 3. Zeta potential values of liposomes with a range of DS concentrations $(n=3 \pm \mathrm{SD})$.

PEGylation of DS-free liposomes resulted in a significant increase $(p<0.05)$ in the negativity of zeta potential for both phospholipids. However, despite the apparent differences in ZP values between PEGylated and non-PEGylated DS-liposomes, no statistically significant differences amongst 
DS-loaded liposomes were found. Nevertheless, this might suggest that ZP values might be affected by vesicle size [38].

\subsection{Drug Loading and Entrapment Efficiencies of DS in Liposomes}

In a liposomal dispersion, drug is expected to be entrapped in the liposomal vesicles (in the core for hydrophilic drugs or embedded within the lipid bilayer for hydrophobic drugs). Additionally, this process depends on many factors such as the ion strength and the $\mathrm{pH}$ of the aqueous phase, the incubation time, the drug to lipid loading ratio, the lipid composition and other [39]. However, the excess amount normally remains as crystals suspended, aggregated (within the aqueous phase), or sedimented [40]. During HPH, samples are forced under high pressure through a narrow nozzle orifice followed by several narrow gaps created by the reactors. Samples are then collected and returned to the feeding chamber to start the next cycle. During this process, unentrapped drug particles may be filtered out of the liposomal formulations and trapped between the reactors and in the tubing. Therefore, it is very important to develop methods that can capture both the amount entrapped by liposomes and the actual total amount in the liposomal formulation (the entrapped plus the free drug).

To present an accurate description of loading amounts of DS to liposomes, two efficiencies were calculated. Namely, (1) Drug Loading Efficiency (DLE\%) to calculate the amount of drug loaded into liposomes out of the theoretical total drug amount used in each formulation; and (2) entrapment efficiency $(\mathrm{EE} \%)$ to calculate the amount of DS entrapped in liposomes out of the actual total amount in each liposome formulation after size reduction.

As shown by Figure 4a, DLE\% of DS decreased with increasing drug/lipid ratio $(p<0.05)$ and that was independent of phospholipid composition. For example, the DLE\% of DS in HSPC-liposomes was $91.7 \% \pm 7.1 \%$ for the $5 \mathrm{~mol} \%$, and that was decreased to $48.12 \% \pm 12.0 \%$ for $15 \mathrm{~mol} \%(p<0.05)$. However, DLE\% for all liposomes was generally similar for the same drug/lipid ratio over the formulations regardless phospholipid composition or PEGylation (Figure 3). Similar findings were observed for paclitaxel (PTX)-liposomal formulations, processed by HPH (unpublished data). Whereas, in our previous studies, using probe sonication for size reduction, lipid composition had a significant effect on PTX entrapment efficiency [20]. This suggests that lipid composition and/or PEGylation had a minimal influence on drug loading for liposomes that have undergone size reduction by $\mathrm{HPH}$.

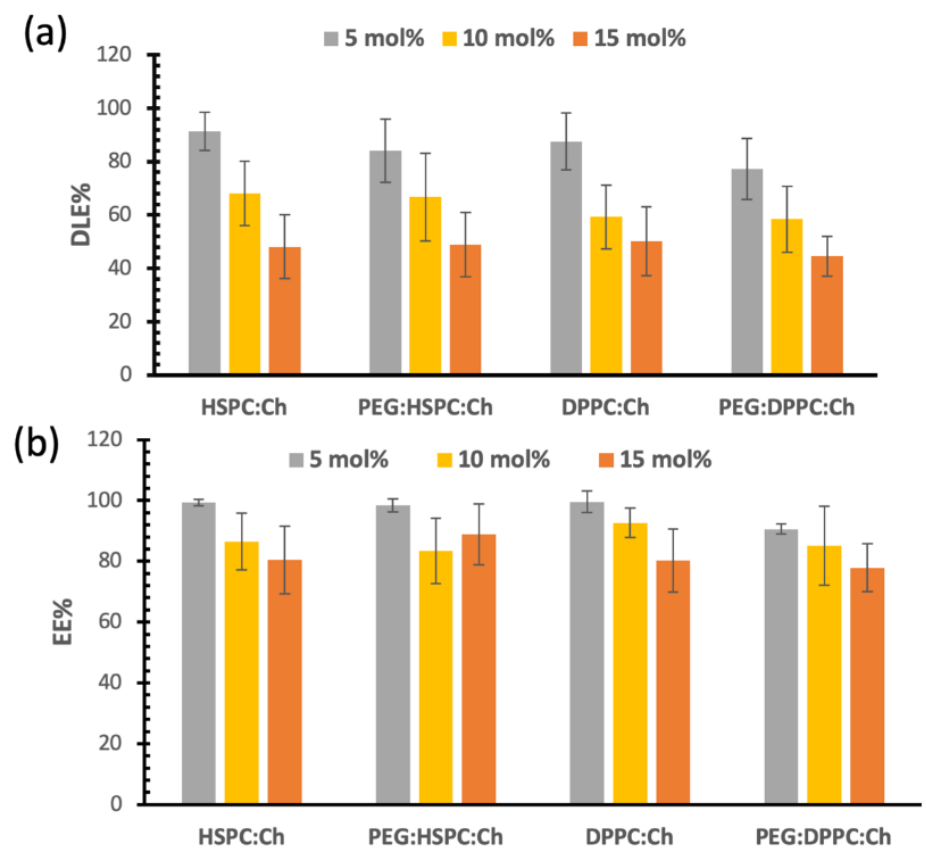

Figure 4. (a) Drug loading efficacies (DLE\%), (b) entrapment efficiency (EE\%). 
Figure 4a also shows that DS loading reached a plateau phase in all formulations at approximately $7 \mathrm{~mol} \%$. More explicitly, for the $10 \mathrm{~mol} \%$ formulations, DLE $\%$ values were around $60 \%-68 \%$, which correlates with 6-6.8 mol\% actual entrapment of DS. Similar calculations for $15 \mathrm{~mol} \%$ will lead to a $7 \mathrm{~mol} \%$ actual entrapment of DS. Therefore, no significant increase in DS loading was observed by increasing the initial loading ratio of DS. These results became more obvious when we observed that the EE\% for all formulations were similar for both $15 \mathrm{~mol} \%$ and $10 \mathrm{~mol} \%$ formulations as shown in Figure $4 \mathrm{~b}$ (no significant differences; $p>0.05$ ). This means that liposome bilayers were not able to entrap greater DS proportions, i.e., a maximum interaction between DS and the phospholipid was reached.

Figure $4 \mathrm{~b}$ presents the entrapment efficiency of DS liposome formulations. Despite the decrease in $\mathrm{EE} \%$ for the 10 and $15 \mathrm{~mol} \%$ compared to that of $5 \mathrm{~mol} \%$, the entrapment efficiencies were above $80 \%$. This indicates that more than $80 \%$ of DS are entrapped in the liposomal vesicles of the final formulations. In other words, less than $20 \%$ of the DS is free in the final formulation. This might be considered-to an extent-a benefit for $\mathrm{HPH}$ as this size reduction technique was able to remove most of the free drug from the final formulation. However, this also might initiate challenges during the scale-up process, such as cleaning the kit after each preparation and validating methods to avoid cross contamination.

We have previously studied the influence of lipid composition (such as HSPC:Ch and DPPC:Ch in equimolar ratios) on the physicochemical properties of formulations and the entrapment efficiency of paclitaxel (PTX) in the liposomes [20]. In that study, the entrapment efficiency of PTX was found to be dependent on lipid composition with DPPC showing the highest loading efficiency $(4.2 \mathrm{~mol} \%$ at the maximum concentration). Unlike PTX liposomes, DS entrapment showed significantly higher $\mathrm{mol} \%$, almost a double of that found with PTX and without significant difference between HSPC and DPPC. These differences might be due to the difference in the physiochemical properties between DS and PTX, although both are lipophilic drugs. A main difference between DS and PTX is that the molecular weight is two-times more for PTX than that of DS; this might explain the higher mol\% entrapment for DS.

It appears that the molecular weight of the loaded drug plays an important role in controlling loading efficiency. For large molecules such as PTX, the maximum loading concertation was found to be $3-4.2 \mathrm{~mol} \%[15,20]$. However, maximum loading concentration as high as $11.2 \mathrm{~mol} \%$ was reported for smaller molecules such as brucine [41]. Many other factors may also influence maximum loading, such as the electrostatic interaction between the drug and polar head groups, which is beyond the scope of the current study and more investigations are needed in the future.

\subsection{Stability Studies in Horse Serum}

Although the anticancer activity of DS has been known for many years, its application in cancer therapy is limited by its instant degradation in the bloodstream $\left(\mathrm{t}_{1 / 2}<4 \mathrm{~min}\right)$ [8]. The orally administrated DS undergoes extensive first-pass metabolism in the liver; hence, the oral administration of DS is not suitable for cancer treatment. This may explain the disappointing results from several oral DS-based cancer clinical trials according to ClinicalTrials.gov (http://www.clinicaltrials.gov/).

Liposomes are already established as anticancer drug delivery systems with evidence of capability to overcome the undesirable physicochemical properties of many anticancer drugs. Liposome-loaded DS formulations can be applied intravenously to deliver the drug at cancer cells; this can avoid liver-enrichment and protect the essential thiol groups on their way to the cancer site. In this study, DS was encapsulated into liposomes and PEGylation was used to further extend the half-life of DS and provide further prospective long circulation in the blood. The stability of DS was studied in horse serum to investigate the efficiency of resulting PEGylated liposomes to protect DS.

As shown in Figure 5, both HSPC and DPPC liposomes demonstrated similar stability profiles, with significantly $(p<0.05)$ enhanced stability of loaded DS compared to that of the free drug. Almost $70 \%$ of free DS was degraded within the first $20 \mathrm{~min}$, whereas an equal amount of loaded DS at both HSPC and 
DPPC liposomes took more than one hour to disappear. Furthermore, this time was extended to more than three hours upon PEGylation, regardless of the phospholipid composition. These differences are confirmed by the half-lives of DS in horse serum, which are extended by approximately three-fold for DS-loaded HSPC (25.8 $\pm 6.5 \mathrm{~min})$ and DPPC (28.7 $\pm 4.5 \mathrm{~min})$ compared to that of free DS $(9.7 \pm 2.3 \mathrm{~min})$. The longest half-lives of DS were obtained after PEGylation; $71.9 \pm 12.3$ min for PEG-HSPC and $77.3 \pm 9.6 \mathrm{~min}$ for PEG-DPPC (Figure 5b). Although the results show a slight difference between HSPC and DPPC liposomes, no statistically significant difference $(p>0.05)$ was observed between both phospholipids.

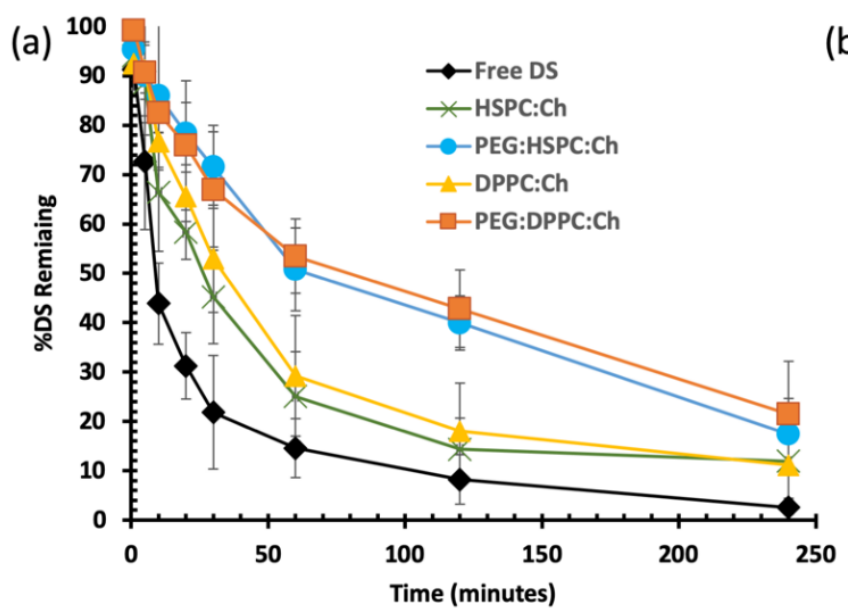

(b)

\begin{tabular}{ll}
\hline Formulation & DSt $_{1 / 2} \pm \mathrm{SD}(\min )$ \\
\hline Free DS & $9.7 \pm 2.3$ \\
HSPC:CH & $25.8 \pm 6.5$ \\
PEG:HSPC:CH & $71.9 \pm 12.3$ \\
DPPC:CH & $28.7 \pm 4.5$ \\
PEG:DPPC:CH & $77.3 \pm 9.6$ \\
\hline
\end{tabular}

Figure 5. The influence of liposomal formulation on the stability of DS in horse serum: (a) degradation curves and (b) the half-lives $\left(\mathrm{t}_{1 / 2}\right)$ of DS in different formulations.

PEGylation has been used in many studies to enhance the stability and prolong the circulation of liposomes in vivo. The mechanisms protective action of PEG has been extensively investigated. One of the most popular opinions is that the interactions of blood components with the liposome surface are sterically hindered by the PEG coating the liposomes. This averts opsonization and uptake by the mononuclear phagocyte system (MPS) [42,43]. Furthermore, surface modification of liposomes by a soluble, well hydrated and chemically inert polymer (PEG), will decrease the surface hydrophobicity and increase the repulsive interactions between colloidal particles (i.e., less liposome aggregation and reduced binding of plasma proteins) $[42,44]$.

PEG liposomal formulations have been successfully used to resolve drug delivery problems of many drugs. For example, the first FDA-approved PEGylated liposomal formulation, Doxil ${ }^{\circledR}$, exhibited prolonged retention in vivo and improved therapeutic effects [45]. However, for some drugs, such as vincristine, the result was unsatisfactory because its rapid leakage compromised its prolonged circulation [43]. Therefore, using PEGylated liposomes should be subjected to in depth investigation, on a case by case basis, depending on the drug and proposed application.

In this study, we found that PEGylated liposomes have a great potential for improving the stability of DS and provide a prospective prolonged circulation in the blood. These results are also supported by a recent study using DSPE-PEG 2000 -based PEGylated copper oleate liposome $(\mathrm{Cu}(\mathrm{OI}) 2-\mathrm{L})$ for targeted delivery in cancer. Pharmacokinetic studies demonstrated that $\mathrm{Cu}(\mathrm{OI}) 2-\mathrm{L}$ had a prolonged circulation time compared to that of injected copper oleate solution [46]. However, no stability study results in serum were shown and the feasibility (and compatibility) of combining DS with $\mathrm{Cu}^{+2}$ in the same dosage form should be investigated in depth. For our study, more investigation is needed to explore the long-term stability of the liposomal formulations and their ability to protect DS in vivo. This has been already listed on to our future plans. 


\subsection{Cytotoxicity Studies}

When repetitively exposed to chemotherapeutics, cancer cells become more resistance and aggressive. This is considered as one of the major hurdles to successful chemotherapy. In this study, 5-fluorouracil (5FU)-resistant colon cancer cell line $\mathrm{H}_{630_{\mathrm{R} 10}}$ and their parental wide-type (sensitive) cell line $\mathrm{H} 630_{\mathrm{WT}}$ were used to determine the cytotoxicity of liposomes loaded with a range of DS concentrations using the MTT assay. The resistant cancer cells are commonly cross-resistant to a wide range of anticancer drugs, Figure 6 shows that $\mathrm{H}_{63} \mathrm{R}_{\mathrm{R} 10}$ cell lines were not only resistant to $5 \mathrm{FU}$, but also resistant to PTX at concentrations higher than $1000 \mathrm{nM}$, whereas the sensitive $\mathrm{H} 630_{\mathrm{WT}}$ were completely killed at concentration far below $1000 \mathrm{nM}$. These results are confirmed by $\mathrm{IC}_{50}$ being above $1000 \mathrm{nM}$ and $43.63 \pm 15.21$ for PTX $(p<0.01)$ in $\mathrm{H}_{630_{\mathrm{R} 10}}$ and $\mathrm{H} 630_{\mathrm{WT}}$ cell lines, respectively (Table 2). The microscopy images taken $72 \mathrm{~h}$ after treatment also confirm that $\mathrm{H} 630_{\mathrm{WT}}$ cell line, showing apoptotic signs, were affected by both drugs 5FU and PTX. On the other hand, H630 10 cell lines were not affected by both 5FU and PTX at the same corresponding concentrations and showed no features of apoptosis (Figure 7).
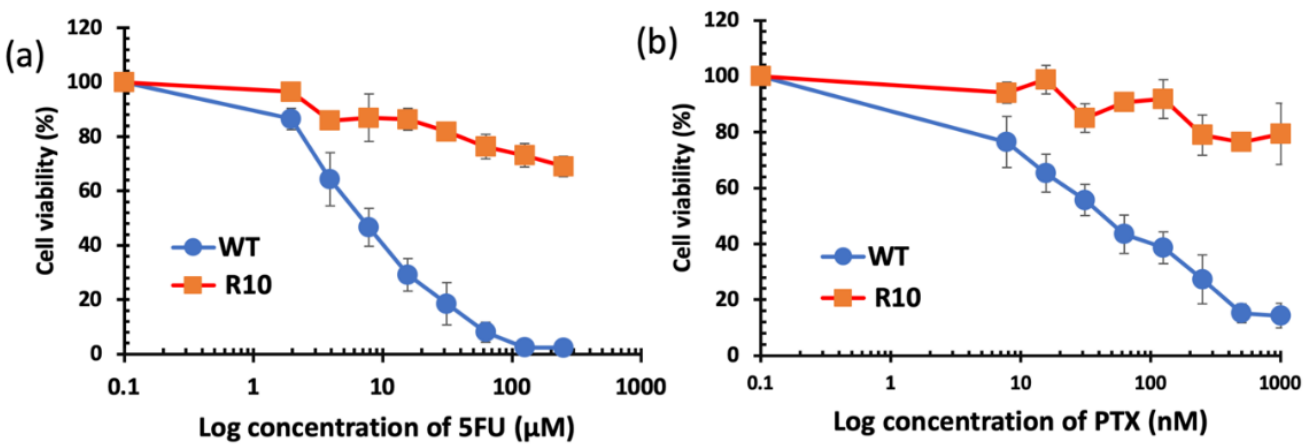

Figure 6. Survival curves (MTT cytotoxicity assay) of colorectal cancer cell lines $\mathrm{H}_{63} \mathrm{WT}_{\mathrm{WT}}$ and $\mathrm{H} 630_{\mathrm{R} 10}$ with increasing concentrations of 5FU (a) and PTX (b) $(n=3 \pm \mathrm{SD})$.

Table 2. The $\mathrm{IC}_{50} \%$ values of DS formulations on both $\mathrm{H} 630_{\mathrm{WT}}$ and $\mathrm{H} 630_{\mathrm{R} 10}(n=3 \pm \mathrm{SD})$.

\begin{tabular}{ccc}
\hline IC $_{\mathbf{5 0}}$ & H630 WT (nM) & H630 R10 (nM) \\
\hline 5FU & $3420 \pm 630.0$ & $>250,000$ \\
PTX & $43.63 \pm 15.21$ & $>1000$ \\
DS/Cu & $57.736 \pm 11.08$ & $49.092 \pm 8.20$ \\
HSPC:Ch & $75.544 \pm 22.68$ & $73.094 \pm 12.28$ \\
PEG:HSPC:Ch & $69.076 \pm 3.95$ & $56.800 \pm 3.21$ \\
DPPC:Ch & $76.273 \pm 10.97$ & $64.69 \pm 10.88$ \\
PEG:DPPC:Ch & $71.289 \pm 10.81$ & $56.165 \pm 21.16$ \\
\hline
\end{tabular}

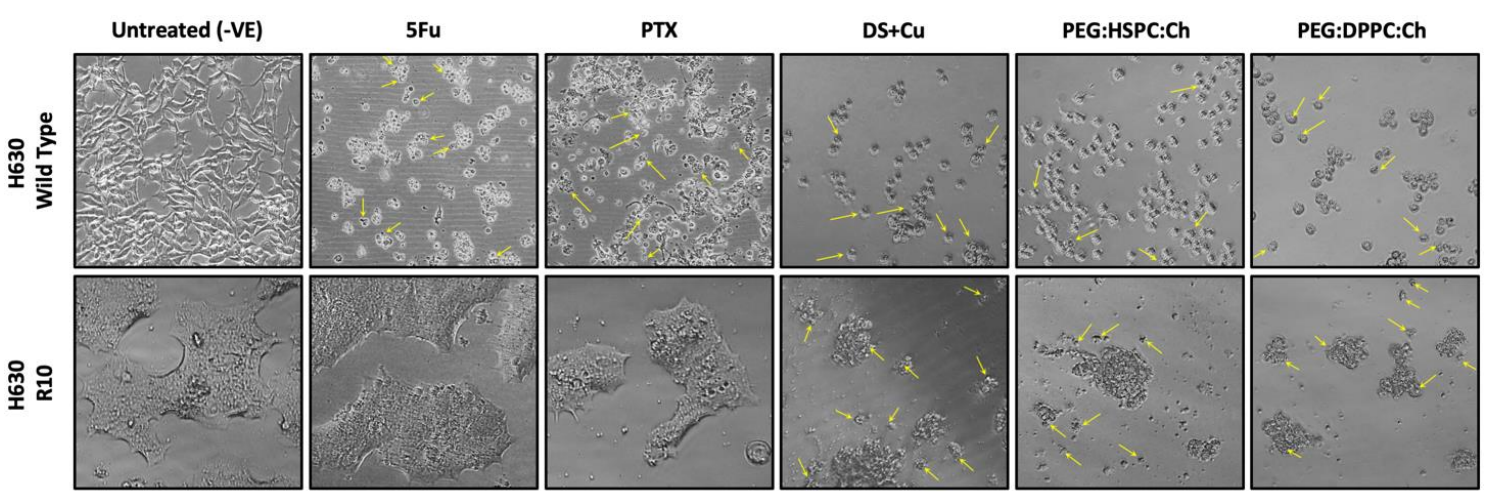

Figure 7. The morphology ( $\times 100$ magnification) of parental and resistant cells after $72 \mathrm{~h}$ of exposure to 5FU $(100 \mu \mathrm{M})$, PTX (125 nM), and DS formulations (equivalent to $125 \mathrm{~nm}$ of DS). The arrows are pointing to features of apoptosis. 
Figure 8 shows the effect of DS liposome formulations on the viability of $\mathrm{H} 630_{\mathrm{R} 10}$ and $\mathrm{H} 630_{\mathrm{WT}}$ cells. Cell viabilities of both cell lines were dependent on drug concentrations regardless phospholipid type $(p<0.05)$. The empty liposomes (no DS), used as a negative control, had no effect on the viability of both cell lines (Figure S3). This may suggest that the remaining ethanol resulting from the preparation methods had no contribution to the cytotoxicity of DS-loaded formulations. For both cell lines, DS completely inhibited the cell proliferation at the highest concentration ( $250 \mathrm{nM})$. Despite the apparent trend showing that the cytotoxicity of DS alone on both cell lines was also higher than that entrapped in liposome formulations, no statistically significant difference was found between the free and encapsulated drug (Figure 8, Table 2). Similarly, $\mathrm{IC}_{50}$ values of DS formulations show that the DS and its liposomal formulations were more toxic toward $\mathrm{H} 630_{\mathrm{R} 10}$ than the sensitive cells $\mathrm{H} 630_{\mathrm{WT}}$; these differences are statistically insignificant $(p>0.05)$. The apparent reduced cytotoxicity of DS in liposome formulations might be attributed to the slow release profile of the drug from the formulations (Figure S1), or to nutritious lipids forming liposomes. It is worth noting that PEGylation had no significant effect $(p>0.05)$ on the cytotoxicity profiles of HSPC or DPPC DS-loaded liposomes despite the apparent differences amongst $\mathrm{IC}_{50}$ values for PEGylated and non-PEGylated liposomes. More investigation is necessary to study the influence of PEGylation on the cellular uptake of DS-loaded liposomes. However, we believe that the cytotoxicity of DS-loaded liposomes is more dependent on the DS release form the liposome rather than liposomal interaction with the cellular membrane.

(a)

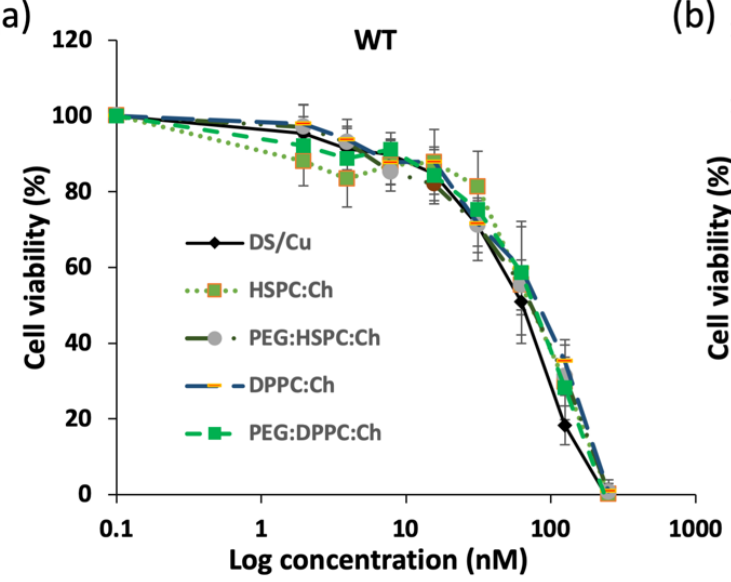

(b)

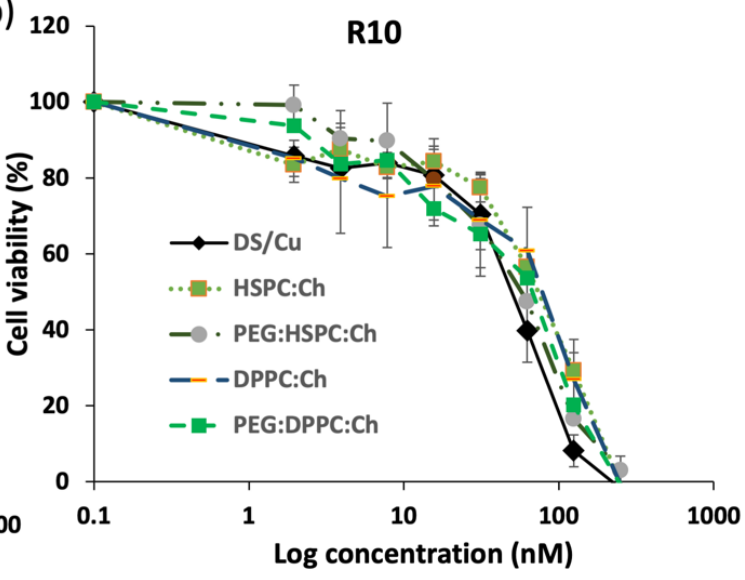

Figure 8. Survival curves of the MTT cytotoxicity assay for DS formulations on colorectal cancer cell lines (a) $\mathrm{H} 630_{\mathrm{WT}}$ and (b) $\mathrm{H} 630_{\mathrm{R} 10}(n=3 \pm \mathrm{SD})$.

The cytotoxic effect of DS liposomal formulations was confirmed by microscopy images taken after $72 \mathrm{~h}$ of exposure to the tested formulations (Figure 7). Both the H630 ${ }_{\mathrm{WT}}$ and $\mathrm{H} 630_{\mathrm{R} 10}$ cells demonstrated apoptotic morphologies (cell blebbing and nuclear condensation and fragmentation) for DS and its PEGylated liposomoal formulations. Similarly, as mentioned earlier, apoptotic morphology was shown by $\mathrm{H}_{63} 0_{\mathrm{WT}}$ after exposure to PTX. In contrast, PTX had no effect on $\mathrm{H} 630_{\mathrm{R} 10}$ due to pan chemoresistance. To assess any potential synergic effect between DS/Cu and 5FU or PTX, a combination cytotoxicity has been performed using MTT assay. The resistant $\mathrm{H} 630_{\mathrm{R} 10}$ cell lines were exposed to serial concentrations of 5FU or PTX and DS/Cu or its PEGylated formulation PEG:HSPC:Ch. As shown in Figure 9, the combination between DS/Cu and 5FU or PTX resulted in enhanced cytotoxicity which was significantly $(p<0.05)$ higher than the cytotoxic effect observed with each of the drugs applied individually. More importantly, DS/Cu and its PEGylated liposomal formulation were able to reverse the chemoresistance of $\mathrm{H} 630_{\mathrm{R} 10}$. The $\mathrm{IC}_{50}$ values of the combinations were significantly $(p>0.05)$ reduced compared to that of sole exposure to each drug. For example, the $\mathrm{IC}_{50}$ value for PEG:HSPC:Ch combined with PTX was $21.81 \pm 4.15$ compared to that PTX alone (over $1000 \mathrm{~nm}$ ). 
(a)

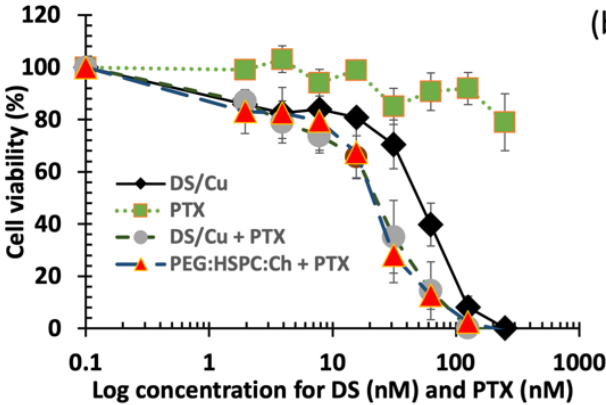

(c)

\begin{tabular}{ll}
\hline Combination & $\mathrm{IC} 50(\mathrm{nM})$ \\
\hline DS/Cu + PTX & $23.66 \pm 6.75$ \\
PEG:HSPC:Ch + PTX & $21.810 \pm 4.15$
\end{tabular}

(b)

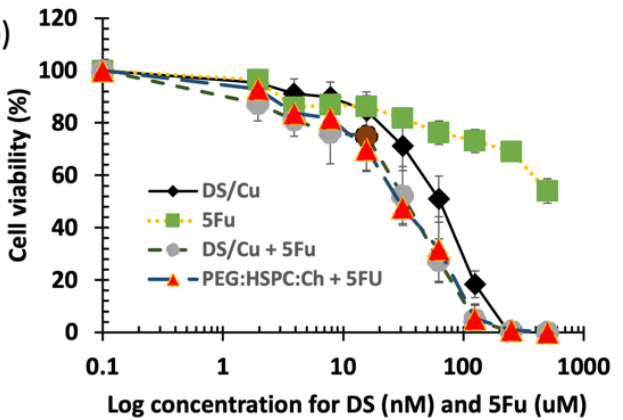

\begin{tabular}{ll}
\hline Combination & $\mathrm{IC} 50(\mathrm{nM})$ \\
\hline DS/Cu + 5FU & $34.47 \pm 8.29$ \\
PEG:HSPC:Ch + 5FU & $29.89 \pm 14.38$
\end{tabular}

Figure 9. The MTT cytotoxicity assay. H630 R10 cell lines were exposed to different concentrations of DS formulations in combination with (a) PTX (b) 5FU. (c) The $\mathrm{IC}_{50}$ values of DS formulations in combination with (a) PTX (b) 5FU $(n=3 \pm$ SD).

Drug-free formulations had no toxic effect on both colorectal cell lines. This has been confirmed previously by several studies; drug-free liposomes displayed a neutral effect on both cancer and normal cell lines in vitro [47]. This may be expected as liposomes are, in general, made of natural biocompatible molecules similar to those forming cellular membranes. Furthermore, liposome vesicles might enhance the efficacy of the drugs by binding to the cells and releasing the therapeutic molecules in a sustained manner $[47,48]$.

In conclusion, in this paper, we have reported the development of PEGylated liposomes of disulfiram using ethanol-based proliposome methods followed by high-pressure homogenisation for size reduction. DS-loaded PEGylated liposomes had relatively smaller sizes and significantly lower polydispersity index than those of conventional liposomes. All liposomal formulations had good entrapment efficiencies and maintained the cytotoxic effect of disulfiram in the presence of copper. More importantly, we found that PEGylated liposomes significantly improved the stability of DS in horse serum. Therefore, PEGylated liposomes might be able to act as potential nanocarriers of DS in cancer therapy. The ability of PEGylated liposomes to protect DS and to provide prolonged circulation in vivo has been already listed in our future plans.

Supplementary Materials: The following are available online at http://www.mdpi.com/1999-4923/11/11/610/s1. Figure S1: the release profiles of DS form liposomes; Figure S2: the $\mathrm{pH}$ values of DS liposomal formulations; Figure S3: survival curves of MTT cytotoxicity assay for the empty liposomal formulations on colorectal cancer cell lines (a) H630WT and (b) H630R10.

Author Contributions: Conceptualization, M.N. and W.W.; methodology, M.N, A.M.A.E. and V.K.; validation, M.N., A.S.S., S.K. and I.T.; formal analysis, M.N.; investigation, M.N., A.S.S., S.K. and I.T; writing-original draft preparation, M.N.; writing-review and editing, I.T., A.M.A.E., V.K. and W.W.; supervision, M.N.

Funding: This research received no external funding.

Acknowledgments: This study was made possible by a research sabbatical grant provided by Anglia Ruskin University and by the support of NPRP grant (NPRP9-337-3-069) from the Qatar National Research Fund (a member of Qatar Foundation). The findings herein reflect the work, and are solely the responsibility of the authors.

Conflicts of Interest: The authors declare no conflict of interest.

\section{References}

1. Walker, I.; Newell, H. Do molecularly targeted agents in oncology have reduced attrition rates? Nat. Rev. Drug Discov. 2009, 8, 15-16. [CrossRef] [PubMed]

2. Reed, M.D. The Rescue and Repurposing of Pharmaceuticals: Augmenting the Drug Development Paradigm. J. Pediatr. Pharmacol. Ther. 2016, 21, 4-6. [CrossRef] [PubMed] 
3. Liu, P.; Wang, Z.; Brown, S.; Kannappan, V.; Tawari, P.E.; Jiang, W.; Irache, J.M.; Tang, J.Z.; Britland, S.; Armesilla, A.L.; et al. Liposome encapsulated Disulfiram inhibits NFKB pathway and targets breast cancer stem cells in vitro and in vivo. Oncotarget 2014, 5, 7471-7485. [CrossRef] [PubMed]

4. Liu, P.; Kumar, I.S.; Brown, S.; Kannappan, V.; Tawari, P.E.; Tang, J.Z.; Jiang, W.; Armesilla, A.L.; Darling, J.L.; Wang, W. Disulfiram targets cancer stem-like cells and reverses resistance and cross-resistance in acquired paclitaxel-resistant triple-negative breast cancer cells. Br. J. Cancer 2013, 109, 1876-1885. [CrossRef]

5. Guo, X.; Xu, B.; Pandey, S.; Goessl, E.; Brown, J.; Armesilla, A.L.; Darling, J.L.; Wang, W. Disulfiram/copper complex inhibiting NFkappaB activity and potentiating cytotoxic effect of gemcitabine on colon and breast cancer cell lines. Cancer Lett. 2010, 290, 104-113. [CrossRef]

6. Liu, P.; Brown, S.; Goktug, T.; Channathodiyil, P.; Kannappan, V.; Hugnot, J.-P.; Guichet, P.-O.; Bian, X.; Armesilla, A.L.; Darling, J.L.; et al. Cytotoxic effect of disulfiram/copper on human glioblastoma cell lines and ALDH-positive cancer-stem-like cells. Br. J. Cancer 2012, 107, 1488-1497. [CrossRef]

7. Viola-Rhenals, M.; Patel, K.R.; Jaimes-Santamaria, L.; Wu, G.; Liu, J.; Dou, Q.P. Recent Advances in Antabuse (Disulfiram): The Importance of its Metal-binding Ability to its Anticancer Activity. Curr. Med. Chem. 2018, 25, 506-524. [CrossRef]

8. Tawari, P.E.; Wang, Z.; Najlah, M.; Tsang, C.W.; Kannappan, V.; Liu, P.; McConville, C.; He, B.; Armesilla, A.L.; Wang, W. The cytotoxic mechanisms of disulfiram and copper(ii) in cancer cells. Toxicol. Res. 2015, 4, 1439-1442. [CrossRef]

9. Wang, F.; Jiao, P.; Qi, M.; Frezza, M.; Dou, Q.P.; Yan, B. Turning Tumor-Promoting Copper into an Anti-Cancer Weapon via High-Throughput Chemistry. Curr. Med. Chem. 2010, 17, 2685-2698. [CrossRef]

10. Safi, R.; Nelson, E.R.; Chitneni, S.K.; Franz, K.J.; George, D.J.; Zalutsky, M.R.; McDonnell, D.P. Copper signaling axis as a target for prostate cancer therapeutics. Cancer Res. 2014, 74, 5819-5831. [CrossRef]

11. Johansson, B. A review of the pharmacokinetics and pharmacodynamics of disulfiram and its metabolites. Acta Psychiatr. Scand. 1992, 86, 15-26. [CrossRef] [PubMed]

12. Wang, Z.; Tan, J.; McConville, C.; Kannappan, V.; Tawari, P.E.; Brown, J.; Ding, J.; Armesilla, A.L.; Irache, J.M.; Mei, Q.-B.; et al. Poly lactic-co-glycolic acid controlled delivery of disulfiram to target liver cancer stem-like cells. Nanomedicine 2017, 13, 641-657. [CrossRef] [PubMed]

13. Butcher, K.; Kannappan, V.; Kilari, R.S.; Morris, M.R.; McConville, C.; Armesilla, A.L.; Wang, W. Investigation of the key chemical structures involved in the anticancer activity of disulfiram in A549 non-small cell lung cancer cell line. BMC Cancer 2018, 18, 753. [CrossRef] [PubMed]

14. Najlah, M.; Ahmed, Z.; Iqbal, M.; Wang, Z.; Tawari, P.; Wang, W.; McConville, C. Development and characterisation of disulfiram-loaded PLGA nanoparticles for the treatment of non-small cell lung cancer. Eur. J. Pharm. Biopharm. 2017, 112, 224-233. [CrossRef]

15. Koudelka, S.; Turánek, J. Liposomal paclitaxel formulations. J. Control. Release 2012, 163, 322-334. [CrossRef]

16. Brown, S.; Khan, D.R. The treatment of breast cancer using liposome technology. J. Drug Deliv. 2012, 2012, 212965. [CrossRef]

17. Pauli, G.; Tang, W.-L.; Li, S.-D. Development and Characterization of the Solvent-Assisted Active Loading Technology (SALT) for Liposomal Loading of Poorly Water-Soluble Compounds. Pharmaceutics 2019, 11, 465. [CrossRef]

18. Palchetti, S.; Caputo, D.; Digiacomo, L.; Capriotti, A.L.; Coppola, R.; Pozzi, D.; Caracciolo, G. Protein Corona Fingerprints of Liposomes: New Opportunities for Targeted Drug Delivery and Early Detection in Pancreatic Cancer. Pharmaceutics 2019, 11, 31. [CrossRef]

19. Wang, W. Disulfiram Formulation and Uses Thereof. WO2012076897A1, 14 June 2012.

20. Najlah, M.; Jain, M.; Wan, K.-W.; Ahmed, W.; Alhnan, M.A.; Phoenix, D.A.; Taylor, K.M.G.; Elhissi, A. Ethanol-based proliposome delivery systems of paclitaxel for in vitro application against brain cancer cells. J. Liposome Res. 2018, 28, 74-85. [CrossRef]

21. Perrett, S.; Golding, M.; Williams, W.P. A Simple Method for the Preparation of Liposomes for Pharmaceutical Applications: Characterization of the Liposomes. J. Pharm. Pharmacol. 1991, 43, 154-161. [CrossRef]

22. Subramanian, S.; Khan, I.; Korale, O.; Alhnan, M.A.; Ahmed, W.; Najlah, M.; Taylor, K.M.; Elhissi, A. A simple approach to predict the stability of phospholipid vesicles to nebulization without performing aerosolization studies. Int. J. Pharm. 2016, 502, 18-27. [CrossRef] [PubMed] 
23. Najlah, M.; Hidayat, K.; Omer, H.K.; Mwesigwa, E.; Ahmed, W.; AlObaidy, K.G.; Phoenix, D.A.; Elhissi, A. A facile approach to manufacturing non-ionic surfactant nanodipsersions using proniosome technology and high-pressure homogenization. J. Liposome Res. 2015, 25, 32-37. [CrossRef] [PubMed]

24. Nii, T.; Ishii, F. Encapsulation efficiency of water-soluble and insoluble drugs in liposomes prepared by the microencapsulation vesicle method. Int. J. Pharm. 2005, 298, 198-205. [CrossRef] [PubMed]

25. Ishii, F.; Nagasaka, Y. Simple and Convenient Method for Estimation of Marker Entrapped in Liposomes. J. Dispers. Sci. Technol. 2001, 22, 97-101. [CrossRef]

26. Ramadhani, N.; Shabir, M.; McConville, C. Preparation and characterisation of Kolliphor ${ }^{\circledR}$ P 188 and P 237 solid dispersion oral tablets containing the poorly water soluble drug disulfiram. Int. J. Pharm. 2014, 475, 514-522. [CrossRef]

27. Shergill, M.; Patel, M.; Khan, S.; Bashir, A.; McConville, C. Development and characterisation of sustained release solid dispersion oral tablets containing the poorly water soluble drug disulfiram. Int. J. Pharm. 2016, 497, 3-11. [CrossRef]

28. Song, W.; Tang, Z.; Lei, T.; Wen, X.; Wang, G.; Zhang, D.; Deng, M.; Tang, X.; Chen, X. Stable loading and delivery of disulfiram with mPEG-PLGA/PCL mixed nanoparticles for tumor therapy. Nanomed.: Nanotechnol. Biol. Med. 2016, 12, 377-386. [CrossRef]

29. Plumb, J.A.; Milroy, R.; Kaye, S.B. Effects of the $\mathrm{pH}$ dependence of 3-(4,5-dimethylthiazol-2-yl)-2,5-diphenyl-tetrazolium bromide-formazan absorption on chemosensitivity determined by a novel tetrazolium-based assay. Cancer Res. 1989, 49, 4435-4440.

30. Urakami, K.; Kobayashi, C.; Miyazaki, Y.; Nishijima, K.; Yoshimura, Y.; Hashimoto, K. Degradation products generated by sonication of benzyl alcohol, a sample preparation solvent for the determination of residual solvents in pharmaceutical bulks, on capillary gas chromatography. Chem. Pharm. Bull. 2000, 48, 1299-1303. [CrossRef]

31. Mui, B.; Chow, L.; Hope, M.J. Extrusion technique to generate liposomes of defined size. Meth. Enzymol. 2003, 367, 3-14.

32. Barnadas Rodríguez, R.; Sabés Xamaní, M. Liposomes prepared by high-pressure homogenizers. Meth. Enzymol. 2003, 367, 28-46. [PubMed]

33. Sriwongsitanont, S.; Ueno, M. Effect of a PEG lipid (DSPE-PEG2000) and freeze-thawing process on phospholipid vesicle size and lamellarity. Colloid Polym. Sci. 2004, 282, 753-760. [CrossRef]

34. Kontogiannopoulos, K.N.; Tsermentseli, S.K.; Assimopoulou, A.N.; Papageorgiou, V.P. Sterically stabilized liposomes as a potent carrier for shikonin. J. Liposome Res. 2014, 24, 230-240. [CrossRef] [PubMed]

35. Tenzel, R.A.; Aitcheson, D.F. Preparation of Uniform-Size Liposomes and Other Lipid Structures. WO1989011335A1, 30 November 1989.

36. Dadashzadeh, S.; Mirahmadi, N.; Babaei, M.H.; Vali, A.M. Peritoneal retention of liposomes: Effects of lipid composition, PEG coating and liposome charge. J. Control. Release 2010, 148, 177-186. [CrossRef]

37. Tsermentseli, S.K.; Kontogiannopoulos, K.N.; Papageorgiou, V.P.; Assimopoulou, A.N. Comparative Study of PEGylated and Conventional Liposomes as Carriers for Shikonin. Fluids 2018, 3, 36. [CrossRef]

38. Howard, F.B.; Levin, I.W. Lipid vesicle aggregation induced by cooling. Int. J. Mol. Sci. 2010, 11, 754-761. [CrossRef]

39. Wang, C.-H.; Huang, Y.-Y. Encapsulating protein into preformed liposomes by ethanol-destabilized method. Artif. Cell Blood Substit. Immobil. Biotechnol 2003, 31, 303-312. [CrossRef]

40. Khan, I.; Yousaf, S.; Subramanian, S.; Korale, O.; Alhnan, M.A.; Ahmed, W.; Taylor, K.M.G.; Elhissi, A. Proliposome powders prepared using a slurry method for the generation of beclometasone dipropionate liposomes. Int. J. Pharm. 2015, 496, 342-350. [CrossRef]

41. Chen, J.; He, C.-Q.; Lin, A.-H.; Xu, F.; Wang, F.; Zhao, B.; Liu, X.; Chen, Z.-P.; Cai, B. Brucine-loaded liposomes composed of HSPC and DPPC at different ratios: In vitro and in vivo evaluation. Drug Dev. Ind. Pharm. 2014, 40, 244-251. [CrossRef]

42. Torchilin, V.P.; Trubetskoy, V.S. Which polymers can make nanoparticulate drug carriers long-circulating? Adv. Drug Deliv. Rev. 1995, 16, 141-155. [CrossRef]

43. Wang, X.; Song, Y.; Su, Y.; Tian, Q.; Li, B.; Quan, J.; Deng, Y. Are PEGylated liposomes better than conventional liposomes? A special case for vincristine. Drug Deliv. 2016, 23, 1092-1100. [CrossRef] [PubMed]

44. Immordino, M.L.; Dosio, F.; Cattel, L. Stealth liposomes: Review of the basic science, rationale, and clinical applications, existing and potential. Int. J. Nanomed. 2006, 1, 297-315. 
45. Barenholz, Y. Doxil ${ }^{\circledR}$ _The first FDA-approved nano-drug: Lessons learned. J. Control. Release 2012, 160, 117-134. [CrossRef] [PubMed]

46. Zhou, L.; Yang, L.; Yang, C.; Liu, Y.; Chen, Q.; Pan, W.; Cai, Q.; Luo, L.; Liu, L.; Jiang, S.; et al. Membrane Loaded Copper Oleate PEGylated Liposome Combined with Disulfiram for Improving Synergistic Antitumor Effect In Vivo. Pharm. Res. 2018, 35, 147. [CrossRef]

47. Al-Suwayeh, S.A.; Tebbett, I.R.; Wielbo, D.; Brazeau, G.A. In Vitro-In Vivo Myotoxicity of Intramuscular Liposomal Formulations. Pharm. Res. 1996, 13, 1384-1388. [CrossRef]

48. Liu, Y.; Ji, M.; Wong, M.K.; Joo, K.-I.; Wang, P. Enhanced therapeutic efficacy of iRGD-conjugated crosslinked multilayer liposomes for drug delivery. Biomed Res. Int. 2013, 2013, 378380. [CrossRef]

(C) 2019 by the authors. Licensee MDPI, Basel, Switzerland. This article is an open access article distributed under the terms and conditions of the Creative Commons Attribution (CC BY) license (http://creativecommons.org/licenses/by/4.0/). 